\title{
Cryopreservation and IVF in the time of Covid-19: what is the best good tissue practice (GTP)?
}

\author{
Kimball O. Pomeroy ${ }^{1}$ (D) Mitchel C. Schiewe $^{2}$
}

Received: 10 June 2020 / Accepted: 24 July 2020 / Published online: 3 August 2020

(C) Springer Science+Business Media, LLC, part of Springer Nature 2020

\begin{abstract}
Examine good tissue practices as relates to in vitro fertilization, biopsying, and vitrificationto compare current knowledge of ova, sperm, and embryos as vectors for disease transmission as it relates to our current knowledge regarding the SARS-CoV-2 virus.

Unknown risks relating to the SARS-CoV-2 virus and sperm, ova, and embryos necessitate a reexamining of how human IVF is performed. Over the last decade, improvements in cryosurvival and live birth outcomes have been associated with zona pellucida breaching procedures (e.g., blastocyst collapsing and biopsying). In turn, today embryos are generally no longer protected by an intact zona pellucida when vitrified and in cryostorage. Additionally, high security storage containers have proven to be resilient to potential cross-contamination and reliable for routine human sperm freezing and embryo vitrification.

Several options to current IVF practices are presented that can effectively mitigate the risks of cross-contamination and infection due to the current Covid-19 pandemic or other viral exposures. The question remains; is heightened security and change warranted where the risks of disease transmission likely remain negligible?
\end{abstract}

Keywords SARS-CoV-2 $\cdot$ Covid-19 $\cdot$ IVF laboratories $\cdot$ Cross-contamination $\cdot$ Good tissue practices

\section{Introduction}

The onset of Covid-19 global pandemic in 2020 has altered all of our lives. We have changed how we function as family units in society and have adapted a safer workplace environment for our staff and patients. Forced to apply preventative measures to potentially control and contain the highly infectious coronavirus specifically known as Severe Acute Respiratory Coronavirus-2 (SARS-CoV-2) in our laboratories, we are once again faced with the inevitable question "What is the risk of disease transmission to and between human embryos, gametes and reproductive tissue in production and cryostorage?" Though it is safe to conclude that the background review and guidance of Pomeroy and

Kimball O. Pomeroy

kopomeroy@gmail.com

Mitchel C. Schiewe

mschiewe@ovationfertility.com

1 The World Egg Bank, Phoenix, AZ 85020, USA

2 Ovation Fertility, Newport Beach, CA 92663, USA colleagues [1] remains valid today, with the former risks of viral transmission being negligible, we must also take a fresh look at the current situation. What has been published or changed in our laboratory practices in the last decade and how do we best adhere to the principles of the Food and Drug Administration's Good Tissue Practice (GTP) guidance?

SARS-CoV-2 is a nasty, infectious airborne virus that is easily spread to any surface for susceptible touch transmission. Interestingly, it is classified as a "wimpy" virus because of its exposed, lipid-containing nuclear envelope (i.e., encasing its deadly RNA) which makes it readily susceptible to disinfection by soapy detergents. Still, it is a killer virus that has our attention. Each person infects about 2.2 people (vs 1.3 for seasonal flu), and its death rate has been estimated at 0.5 to $3.5 \%$ (vs $0.01 \%$ for seasonal flu; the accuracy of these figures has been questioned, especially for the death rate of the seasonal flu) [2] [3]. In the first 6 months of the pandemic at least 270,000 deaths worldwide have been attributed to Covid-19 [3]. Compare this to the 290,000 to 650,000 killed annually worldwide by the seasonal flu [4]. Death is not the only harm a disease can cause; we must also consider morbidity and aspects of SARS-CoV-2related disorders just being realized. How many people will be crippled for life after SARS-CoV-2 infection? 
SARS-CoV-2 holds our attention-it is new and we do not know a lot about it. We learn a little more each day. The important questions we must answer (with incomplete data), as it relates to reproductive treatments, are as follows: (1) Can donor ova, sperm, or embryos vertically transmit Covid-19 to recipients of these tissues? (2) Can SARS-CoV-2 from the tissue of an infected patient be passed on to that patient or their offspring after transfer? (3) Can the presence of SARS$\mathrm{CoV}-2$ in frozen reproductive specimens cross-contaminate tissue stored nearby?

\section{How do we handle potential infectious microorganisms in IVF today?}

Performing IVF in the presence of infectious organisms is not new to reproductive laboratories. There are many infectious diseases potentially present in our laboratories that we know a lot about. They live among us in various concentrations-anthrax, measles, rabies, Rocky Mountain spotted fever, tuberculosis, salmonella, Lyme disease, ZIKA virus, meningococcal diseases, HIV, pneumococcal infections, Bordetella pertussis, hepatitis (A through E), and herpes, just to mention a few.

Each of us contributes to the microbiome in the environment via respiration and the shedding of millions of skin cells each day [5]. Qian et al. quantified microorganism emission rates and found that $3.7 \times 10^{7}$ and $7.3 \times 10^{6}$ bacterial and fungal genome copies, respectively, were emitted per personhour [6]. In short, the air around us contains pathogens, including viruses. Again, this too is not a new concept as Bielanski has previously detailed the cross-contamination cycle between the environment, cryostorage tanks, specimens, and ultimately our in vitro culture systems or patients [7].

Take for example MRSA, which caused 120,000 infections in 2017 and resulted in 20,000 deaths [8]. This bacterium lives in the nasal cavity of many of us. One study found MRSA in almost $25 \%$ of surveyed post-graduate dental students [9]. What about tuberculosis, one of the biggest killers in the world. In 2018, 10 million people were infected worldwide and about 1.5 million died. It is still in the USA and infects about 10,000 annually [10]. Then, there is Rocky Mountain spotted fever, rabies, malaria, measles, and the seasonal flu. What special precautions do we currently take to avoid contaminating embryos, ova, nitrogen storage tanks, or infecting patients?

One would think with all of the microorganisms found on our skin and in our bodily fluids, with all of those found in non-sterile laboratories and non-sterile storage tanks, that there would have been at least one event of crosscontamination or passage of a disease from gametes or embryos to another patient during IVF treatment.

Despite living and working in a soup of microorganisms, including vats of liquid nitrogen, not one case has been identified where either the laboratory treatment of IVF (culture of embryos, cryopreservation, or storage of embryos/ova) has resulted in the production of a disease in a patient or recipient of donor reproductive tissue. This information alone should indicate a very low (i.e., negligible) probability of a SARS-CoV-2 contaminant affecting embryos or embryo recipients. It may also indicate that the methods used today for IVF and cryopreservation will help avoid the passage of Covid-19 via fertility treatment. A lot of this success can be attributed to the fact that ova and embryos are poor vectors for diseases.

In looking at the potential source of infectious diseases affecting patients undergoing IVF, we need to look at the three major tissue sources: sperm, ova, and embryos.

\section{Sperm}

Sperm are ejaculated with a fluid that is not sterile. It is often contaminated with white blood cells, red blood cells, bacteria, and viruses. One study isolated herpes viruses in $83 \%$ of men's semen. Although sperm is often purified from semen using filtration techniques, it can still contain microorganisms. What makes this of concern with SARSCoV-2 is that men that have been infected with Covid-19 have been shown to have the virus in their semen [11]. As of yet, there is no evidence that Covid-19 is sexually transmitted, but the presence of the virus in the semen of sick men is the first evidence that it could be. This is especially important when one is dealing with donor semen. Standard quarantining measures of donors with repeated negative PCR viral testing will likely eliminate SARS-CoV-2 concerns, as this virus has failed to be detected above a minimum threshold of sensitivity after healthy men recover from Covid-19 [12] [13].

It has long been known that the seminal plasma of neat semen harbors the vectors for the possible viral transmission of disease. For example, seven women in the mid-1980s became infected with the HIV virus after donor insemination from HIV-positive men [14]. A simple sperm wash procedure that separates progressive motile sperm from the seminal supernatant reduces HIV levels greater than 10,000-fold among infected patients, simply by dilution [15]. Density gradient centrifugation combined with sperm swim-up further separates seminal components (e.g., lymphocytes) from the motile sperm but does not completely eliminate HIV-1 or HCV RNA. Eventually, Loskutoff and co-workers [16] designed a double lumen centrifugation tube with a side port to load gradient columns and specimens, as well as a central channel to directly sample the pellet cleanly without exposure to gradient contaminates. They later added a middle trypsin layer to effectively lyse surface proteins on the HIV and HCV viruses, followed by soybean trypsin inhibitor in the $90 \%$ layer to deactivate the enzymatic reactions. This device/methodology 
proved to significantly eliminate viral RNA below detectable levels when combined with a two-step wash (i.e., additional dilution effect). Ultimately, the Proinsert device by Nidacon was developed for clinical use [17], and although it has not been clinically validated, it is routinely used to recover viable, motile sperm pellet fractions while minimizing any risk of viral contamination. Therefore, the use of this device and method should logically be applied to all patients suspected or known to be a viral carrier, including SARS-CoV-2.

\section{Ova}

Ova are encased in a protective coat called the zona pellucida (ZP). There is no biological reason though for ova to have ACE-2 receptors, to which SARS-CoV-2 binds. Although there may not be receptors for the SARS-CoV-2 virus on the $\mathrm{ZP}$ or the vitelline membrane of the oocyte, cumulus cells could theoretically contain receptors to the virus. Meanwhile, no studies have been done using human oocytes and SARS$\mathrm{CoV}-2$ to see if the virus will bind to the $\mathrm{ZP}$. If viral binding receptors were verified on its outer surface, and viral risk was confirmed, the concept of a 10-step trypsin wash as adopted by the International Embryo Transfer Society [18] over two decades ago for the exportation of livestock embryos would be an advisable preventative measure.

\section{Embryos}

The answer to whether embryos can become infected by the SARS-CoV-2 virus is still unknown. There is evidence though that blastocysts likely have receptors for the virus [19]. This information has not been adequately examined in a peerreviewed journal yet, and it also remains to be seen whether the embryo can be infected by the virus.

In the last several years, PGT-A and the biopsying of embryos have become quite popular. One must examine the increased risks of infecting an embryo with a virus in a system where the protective coat of the ZP is commonly breached during embryo biopsy. Fortunately, this breach is often made after several passages through solutions, resulting in a significant dilution factor. Embryologists should consider increasing dilution steps to avoid the transfer of viruses when handling embryos before biopsy and vitrification. Since not performing biopsies may not be a realistic probability, other risk mitigating measures have been proposed. In addition, practical liquid nitrogen sterilization methods have been developed and might be useful at minimizing viral exposure risks during vitrification, cryostorage, and warming [20] [21]. This method though was not tested on viruses but instead on bacteria and fungi.

\section{Developments regarding gametes and embryos as disease vectors}

Embryo transfer technologies have long been used to bypass the vertical transmission of diseases between live animals. Such experiences include recovering embryos from donor cattle in Canada in the mid-1970s and transferring them to recipient cows in the USA via live rabbit couriers whose ligated oviducts temporarily incubated the embryos. By avoiding live animal importation of cattle, veterinarians and ranchers circumvented a 7-year USDA quarantine for farm animals harboring potentially deadly diseases. Developed countries have long been concerned about initiating an epidemic in their animal agriculture industry that could financially and physically disrupt the food chain and economy. Today, with the Covid-19 pandemic, we can envision how valid their concerns were. By 1980, the dedicated efforts of scientists began studying the potential for disease transmission between animals and embryos and developed international policies to eliminate risks as previously reviewed [18]. These steps include only using ova and embryos with intact zonas, several rinse steps to dilute out potential pathogens, and the addition of a step to treat the zonas with an enzyme to remove potential bound microbes. In turn, a 10-step pre-freeze embryo washing procedure, including a trypsin exposure step, was adopted for import-export safety reasons. This guidance was aimed at establishing a zero tolerance toward the risks of embryo disease transmission. Interestingly, prior to the adoption of these procedures for washing embryos, no cases of disease transmission by embryos had been reported [1].

Researchers have examined the risks of transferring diseases via embryos. One study looked at the potential for passing on virus via IVF from cattle that were infected with the flavivirus, BVDV [22]. Despite finding virus in the follicular fluid and on the cumulus-oocyte complexes after in vitro maturation of the ova and fertilization via IVF, no virus was detected 7 days later in the developing embryos. A similar study was performed in 24 patients undergoing IVF who were infected with HIV, HBV, and HCV [23]. Despite some patients having high viral titers and the use of open vitrification devices for cryopreservation, virus was not detected in follicular fluid, culture media, liquid nitrogen used for vitrification, or liquid nitrogen used for storage of the embryos. The authors concluded, "our findings provide evidence of the lack of a risk of cross-contamination while handling oocytes or embryos from seropositive patients, even when using an open device for vitrification." The above two studies were done without treatment with special washes or enzymes.

One of the biggest defenses against viral infections from IVF is that routine IVF involves many steps where a small volume $(\sim 1 \mathrm{ul})$ containing the egg or embryo is added to a larger volume ( $\sim 25 \mathrm{ul})$ for fertilization, culture, or just simple 
rinsing. An estimate of the dilution factor from ova retrieval to embryo transfer would be about 1 million to 1 . If vitrification and warming are added, the dilution factor would be well over 1 trillion to 1 . These high dilution factors make it almost impossible for a free-floating virus to be passed along with the ova or embryo.

It should be remembered that most livestock and human studies to examine whether oocytes and embryos can act as vectors were performed on embryos with an intact ZP. There is little knowledge on the effect of cracked zonae or zona-free embryos in disease transmission. In the current practice of performing PGT-A on almost all patient embryos (in the USA), it is impossible to predict what effect the breaching and sometimes removal of the ZP will have on disease transmission. Dilution will also be less effective in cases where the virus has bound to receptors to on the zona pellucida.

\section{Cross-contamination}

The salient studies to be considered for risk assessment analysis which led us to understand that there is no factual evidence that ZP-intact oocytes and embryos are capable of transmitting a disease acquired during the collection of embryos, in vitro fertilization/culture, or while in cryostorage have been previously reviewed [1]. Some of those studies will be briefly mentioned below to place today's ART practices into a renewed perspective.

In assessing potential cross-contamination during cryopreservation and storage, one should remember one simple fact, which is, that no real-life examples of crosscontamination of systems used in the reproductive laboratory have ever resulted in disease transmission. The only recorded case of cross-contamination of tissue samples occurred where bone marrow bags from hepatitis B positive patients stored in liquid nitrogen contaminated nearby bone marrow bags and gave some of those recipients HBV [24]. Conversely, the only known cross-contamination of tissue stored in devices used in IVF was in an experiment conducted by Bielanski et al. [25] where liquid nitrogen was intentionally contaminated with bovine viral diarrhea virus (BVDV), and $21.3 \%$ of nearby open storage devices (cryovials and open-pulled straws) were found to be contaminated with the virus. Importantly, none of the controls, sealed straws and cryovials, was contaminated.

In a similar study [26], where mouse embryos were stored with vials of mouse viruses, no cross-contamination was detected even after storage from 6 months to a year. Viruses were not detected in the liquid nitrogen detritus via PCR nor were any offspring infected from the transfer of virus-exposed embryos. These and other studies indicate that the risk of cross-contamination is indeed a negligible risk.

\section{Does good tissue practices warrant closed devices for storage?}

To avoid cross-contamination, some embryologists have advocated placing all new cryopreserved specimens into a quarantine tank until patients are determined to have negative viral test results at some future time. Once identified as coming from a non-infected patient, the embryos or ova could then be transferred to the main storage tanks. If cross-contamination is a real risk though, why would you expose all new specimens to potential viruses until passing quarantine? Could not cross-contamination occur during quarantine so that the patient's tissue becomes contaminated and then it contaminates all of the supposedly unaffected tissue? The use of aseptic, closed vitrification devices completely alleviates the need for tank separation steps while maintaining the security of the enclosed embryo or gametes from viral exposure at any level.

Although the risk of viral transfection is unproven, risk assessment potential is virtually eliminated in an "aseptic, closed vitrification system" like the high security vitrification (HSV) [27], microSecure vitrification ( $\mu$ S-VTF) [28] [29], and Vitrisafe [30] [31] [32] approaches. Unlike other original sub-optimal closed designs approved by FDA, the latter systems are superior in that their carrier devices are inserted into CryoBioSystem's (CBS) straws. The unique ionomeric resin plastic material of these high security straws innovated the concept of disease prevention in cryostorage containers by creating impermeable weld seals upon impulse warming (see review: [33]). This development literally transformed human semen storage practices in Europe in the mid- to late-1990s. By 2002, CBS straws were the first embryo storage container to be FDA approved based on their ability to form $100 \%$ reliable weld seals, tamperproof internalized labelling, and a variety of color-coding options.

Only the $\mu \mathrm{S}-\mathrm{VTF}$ system fully retained the unique benefits of the original CBS $0.3-\mathrm{ml}$ embryo straw design and has been clinically validated to be highly effective, reliable, and secure system over the last decade [34].

\section{Recommendations: potential modifications to reduce the risks of SARS-CoV-2}

It is difficult to provide hard recommendations to minimize risks in this time of Covid-19 when we know so little about SARS-CoV-2, especially as it relates to titers of the virus in reproductive fluid, the ability of the virus to infect and grow in gametes and embryos, and the timing of when/if gametes and embryos might be exposed to virus. For example, because little is known about post-infection 
immunity to SARS-CoV-2, a patient could conceivably reinfect themselves from the transfer of vitrified embryos that contain contaminating virus. Obviously, it is imperative that laboratory staff apply strict preventative PPE and hygiene measures to maximize safety between individuals and the specimens being handled. Below are steps that should be considered to ameliorate the effect of the virus in patients undergoing IVF. Decisions regarding which steps to implement may change as we acquire more information about SARS-CoV-2.

- At retrieval, ova should be removed as soon as possible from the aspirate and placed in large volumes of media prior to cumulus cell removal. Alternatively, trimming of the greater cumulus complex can be performed on a dish surface while isolating them from the aspirate and then diluting them with fresh holding medium.

- All remaining cumulus cells (i.e., corona radiata) should be removed prior to ICSI, biopsy, or vitrification, followed by repeated rinsing through multiple washes.

- Liquid nitrogen should not be shared among patients for vitrification and warming of open device systems, or alternatively, $\mathrm{LN}_{2}$ bathes should be UV disinfected between uses.

- To reduce the possibility of contamination with SARS-CoV-2, all gametes and embryos should go through extensive washing to dilute out potential viral contamination.

- Biopsied, hatching, and hatched blastocysts should be vitrified in closed systems if there is a risk of viral exposure. To avoid this risk, an earlier transfer or vitrification of embryos may be considered.

- If an imminent viral risk exists, embryos with intact-ZP should be vitrified prior to hatching.

- We should reconsider the extensive use of embryo intracytoplasmic sperm injection, biopsy and PGT-A and the potential risks of exposing a zona-damaged embryo to potential infection from SARS-CoV-2. Potentially, the number of non-essential biopsy cases should be eliminated. This may include reviewing ASRM's guidance on the use of PGT-A [35].

- Embryos with breached zonae should be isolated and not transferred until more information regarding SARS-CoV2 is reviewed.

- Sperm purification systems aimed to process and minimize viral contaminants in semen of positive-tested patient should be used in all patients and the centrifugation of raw semen should be avoided.

- All sperm freezing at risk of viral exposure should be performed in weld-sealed CBS straws, and the sealer surface disinfected between patients.

\section{Summary}

There have been many predictions and recommendations during this pandemic in an effort to minimize its costs to human life and suffering. Change to our current protocols comes with a cost. Ultimately, our patients will bare this cost whether financial or related to safety and success. When one is dealing with an infection where much is unknown, we should examine the worse-case scenarios carefully where patients bear the costs of our actions or inactions. A year from now, we will have more information on which to base our decisions. In the meantime, we must perform a cost/benefit calculation and determine what is the best decision with what we know. What risks are we willing to take and are we actually applying best GTP measures? We must think hard about the worst-case scenario and then ask if we have the right to gamble with our patient's future based on using protocols for the best-case scenario? In conclusion, we need to reassess the full intent of FDA's GTP and adopt safer and more protective procedures. This pandemic has taught us that we do not know what viral insults lie ahead and that prior guidelines and current ART practices make most laboratories and their patients susceptible to risk.

Acknowledgments The authors would like to memorialize this discussion to the memory of Naida Loskutoff, a friend and colleague in animal reproductive physiology whom dedicated her career to conservation biology from the late 1980 s to 2015 . One goal was to overcome barriers in disease transmission regulations through safer ART and cryopreservation practices to disseminate greater global genetic diversity. It was a passion of love and economic struggle not fully appreciated in our field of Reproductive Medicine. Ironically, when the economic rewards of her dedicated efforts were finally realized with the development of the Proinsert device to eliminate HIV and HCV I in human semen, her life was taken too soon for her to fully enjoy the fruits of her labor. As a scientist and friend she is missed!

\section{References}

1. Pomeroy K, Harris S, Conaghan J, Papadakis M, Centola G, Basuray R, et al. Storage of cryopreserved reproductive tissues: evidence that cross-contamination of infectious agents is a negligible risk. Fertil Steril. 2010;94(4):1181-8.

2. Ries J Here's how COVID-19 compares to past outbreaks 5 May 2020. [Online]. Available: https:/www.healthline.com/ health-news/how-deadly-is-the-coronavirus-compared-to-pastoutbreaks\#2009-(H1N1)-flu-pandemic.. [Accessed 5 June 2020].

3. Roser M, Ritchie H, Ortiz-Ospina E, Hasell J, Coronavirus (COVID-19) deaths 3 June 2020. [Online]. Available: https:// ourworldindata.org/covid-deaths\#. [Accessed 5 June 2020].

4. The World Health Organization Influenza (seasonal) The World Health Organization, 6 November 2018. [Online]. Available: https://www.who.int/news-room/fact-sheets/detail/influenza(seasonal). [Accessed 5 June 2020].

5. Prussin A II, Marr LC. Source of airborne microorganisms in the built environment. Microbiome. 2015;3:78-88. 
6. Qian J, Hospodsky D, Yamamoto N, Nazaroff W, Peccia J. Sizeresolved emission rates of airborne bacteria and fungi in an occupied classroom. Indoor Air. 2012;22:339-51.

7. Bielanski A. A review of the risk of contamination of semen and embryos during cryopreservation and measures to limit crosscontamination during banking to prevent disease transmission in ET practices. Theriogenology. 2012;77(3):467-82.

8. Kourtis A, Hatfield K, Baggs J, Mu Y, See I, Epson E, Nadle J, Kainer M, Dumyati G, PetitS, Ray S, Vital signs: epidemiology and recent trends in methicillin-resistant and in methicillin-susceptible Staphylococcus aureus bloodstream infections - United States. 8 March 2019. [Online]. Available: https://www.cdc.gov/mmwr/ volumes $/ 68 / \mathrm{wr} / \mathrm{mm} 6809 \mathrm{e} 1 . \mathrm{htm} \#: \sim$ :text=Invasive $\% 20$ methicillin $\%$ 2Dresistant $\% 20$ Staphylococcus $\% 20$ aureus, of $\% 20$ decline $\%$ 20has $\% 20$ recently $\% 20$ slowed.\&text=Nearly $\% 20120 \% 2 \mathrm{C} 000 \%$ 20Staphylococcus\%20aureus\%20bloodstream,the $\% 20$ United $\%$ 20States\%20in\%202.

9. Hema N, Raj N, Chaithanya E, Chincholi R, Iswariya M, Hema K. J. Oral Maxi Prevalence of nasal carriers of methicillin-resistant Staphylococcus aureus among dental students: an in vivo study. $\mathrm{J}$ Oral Maxillofac Pathol. 2017;21(3):356-9.

10. Division of tuberculosis elimination trends in tuberculosis, 201819 October 2019. [Online]. Available: https://www.cdc.gov/tb/ publications/factsheets/statistics/tbtrends.htm. [Accessed 5 June 2020].

11. Diangeng L, Jin M, Bao P., Zhao W, Zhang S Clinical characteristics and results of semen tests among men with coronavirus disease. 7 May 2020. [Online]. Available: https://jamanetwork.com/ journals/jamanetworkopen/fullarticle/2765654?utm_source=For The_Media\&utm_medium $=$ referral\&utm_campaign $=\mathrm{ftm}_{-}$ links\&utm term $=050720$. [Accessed 5 June 2020].

12. Holtmann $\bar{N}$, Edimiris $P$, Andree M, Doehmen C, Baston-Buest D, Adams O, et al. Assessment of SARS-CoV-2 in human semen - a cohort study. Fertil Steril. In Press.

13. Pan F, Xiao X, Guo J, Song Y, Li H, Patel D, et al. No evidence of SARS-CoV-2 in 393 semen of males recovering from COVID-19. Fertil Steril. 2020;113(6):1135-9.

14. Araneta M, Mascola L, Eller A, O'Neil L, Ginsberg M, Bursaw M, et al. HIV transmission through donor artificial insemination. JAMA. 1995;273(11):854-8.

15. Quayle A, Zu C, Mayer K, Anderson DJ. T lymphocytes and macrophages, but not motile spermatozoa, are a significant source of human immunodeficiency virus in semen. J Infect Dis. 1997;176:960-8.

16. Loskutoff N, Huyser C, Singh R, Tech B, Walker D, Thornhill A, et al. Use of a novel washing method combining multiple density gradients and trypsin for removing human immunodeficiency virus1 and hepatitis C virus from semen. Fertil Steril. 2005;84:1001-10.

17. Dineen T, Woodward B. Other factors to consider with sperm preparation for treatment. In: Jayant Mehta BW, editor. Male infertility: sperm diagnosis, management and delivery. JP Medical Publishers, Ltd: London; 2014. p. 71-80.

18. Givens D, Stringfellow DA. Manual of the International Embryo Transfer Society: a procedural guide and general information for the use of embryo transfer technology, emphasizing sanitary precautions. 4th ed. Champaign: International Embryo Transfer Society; 2008. p. 1-145.

19. Colaco S, Chhabria K, Singh N, Bhide A, Singh SDA, Husein A, Mishra A, Sharma R, Ashary N, Modi D. Expression of SARSCoV-2 receptor ACE2 and the spike protein processing enzymes in developing human embryos. April 2020. [Online]. Available: https://www.researchgate.net/publication/340646795_Expression of_SARS-CoV-2_receptor_ACE2_and_the_spike_protein processing_enzymes_in_developing_human_embryos. [Accessed 5 June 2020].
20. Parmegiani L, Accorsi A, Cognigni G, Bernardi S, Troilo E, Filicori M. Sterilization of liquid nitrogen with ultraviolet irradiation for safe vitrification of human oocytes or embryos. Fertil Steril. 2010;94(4):1525-8.

21. Parmegiani L, Accorsi A, Bernardi S, Arnone A, Cognigni G, Filicori M. A reliable procedure for decontamination before thawing of human specimens cryostored in liquid nitrogen: three washes with sterile liquid nitrogen (SLN2). Fertil Steril. 2012;98(4):870-5.

22. Bielanski A, Dubuc C. In vitro fertilization of ova from cows experimentally infected with a non-cytopathic strain of bovine viral diarrhea virus. Anim Reprod Sci. 1995;38:215-22.

23. Cobo A, Bellver J, de los Santos M, Remohí J. Viral screening of spent culture media and liquid nitrogen samples of oocytes and embryos from hepatitis $\mathrm{B}$, hepatitis $\mathrm{C}$, and human immunodeficiency virus chronically infected women undergoing in vitro fertilization cycles. Fertil Steril. 2012;97(1):74-8.

24. Tedder R, Zuckerman M, Goldstone A, Hawkins A, Fielding A, Briggs E, et al. Hepatitis B transmission from a contaminated cryopreservation tank. Lancet. 1995;346:137-40.

25. Bielanski A, Nadin-Davis S, Sapp T, Lutz-Wallace C. Viral contamination of embryos cryopreserved in liquid nitrogen. Cryobiology. 2000;40(2):110-6.

26. Kyuwa S, Nishikawa T, Kaneko T, Nakashima T, Kawano K, Nakamura N, et al. Experimental evaluation of crosscontamination between cryotubes containing mouse 2-cell embryos and murine pathogens in liquid nitrogen tanks. Exp Anim. 2003;52(1):67-70.

27. Van Landuyt L, Verpoest W, Verheyen G, De Vos A, Van de Velde $\mathrm{H}$, Liebaers I, et al. Closed blastocyst vitrification of biopsied embryos: evaluation of 100 consecutive warming cycles. Hum Reprod. 2010;26:316-22.

28. Schiewe MC, Zozula S, Anderson RE, Fahy GM. Validation of microSecure vitrification $(\mu \mathrm{S}-\mathrm{VTF})$ for the effective cryopreservation of human embryos and oocytes. Cryobiology. 2015;71:264-72.

29. Schiewe MC, Zozula S, Nugent N, Waggoner K, Borba J, Gamboa $\mathrm{L}$, et al. Modified microSecure vitrification: a safe, simple and highly effective cryopreservation procedure for human blastocysts. J Vis Exp. 2017;121:e54871.

30. Panagiotidis Y, Vanderzwalmen P, Prapas Y, Kasapi E, Goudakou M, Papatheodorou A, et al. Open versus closed vitrification of blastocysts from an oocyte-donation programme: a prospective randomized study. Reprod BioMed Online. 2013;26:470-6.

31. Papatheodorou A, Vanderzwalmen P, Panagiotidis Y, Prapas N, Zikopoulos K, Georgiou I, et al. Open versus closed oocyte vitrification system: a prospective randomized study. Reprod BioMed Online. 2013;26:595-602.

32. Wirleitner B, Vanderzwalmen P, Bach M, Baramsai B, Neyer A, Schwerda D, et al. The time aspect in storing vitrified blastocysts: its impact on survival rate, implantation potential and babies born. Hum Reprod. 2013;28:2950-7.

33. Mortimer D. Current and future concepts and practices in human sperm cryobanking. Reprod BioMed Online. 2004;9(2):134-51.

34. Anderson R, Whitney J, Schiewe M. Clinical benefits of preimplantation genetic testing for aneuploidy (PGT-A) for all in vitro fertilization treatment cycles. J Eur Med Genet. 2019;62:103731.

35. Practice Committee of the American Society for Reproductive Medicine and The Society for Assisted Reproductive Technology. The use of preimplantation genetic testing for aneuploidy (PGT-A: a committee opinion). Fertil Steril. 2018;109(3):429-36.

Publisher's note Springer Nature remains neutral with regard to jurisdictional claims in published maps and institutional affiliations. 